
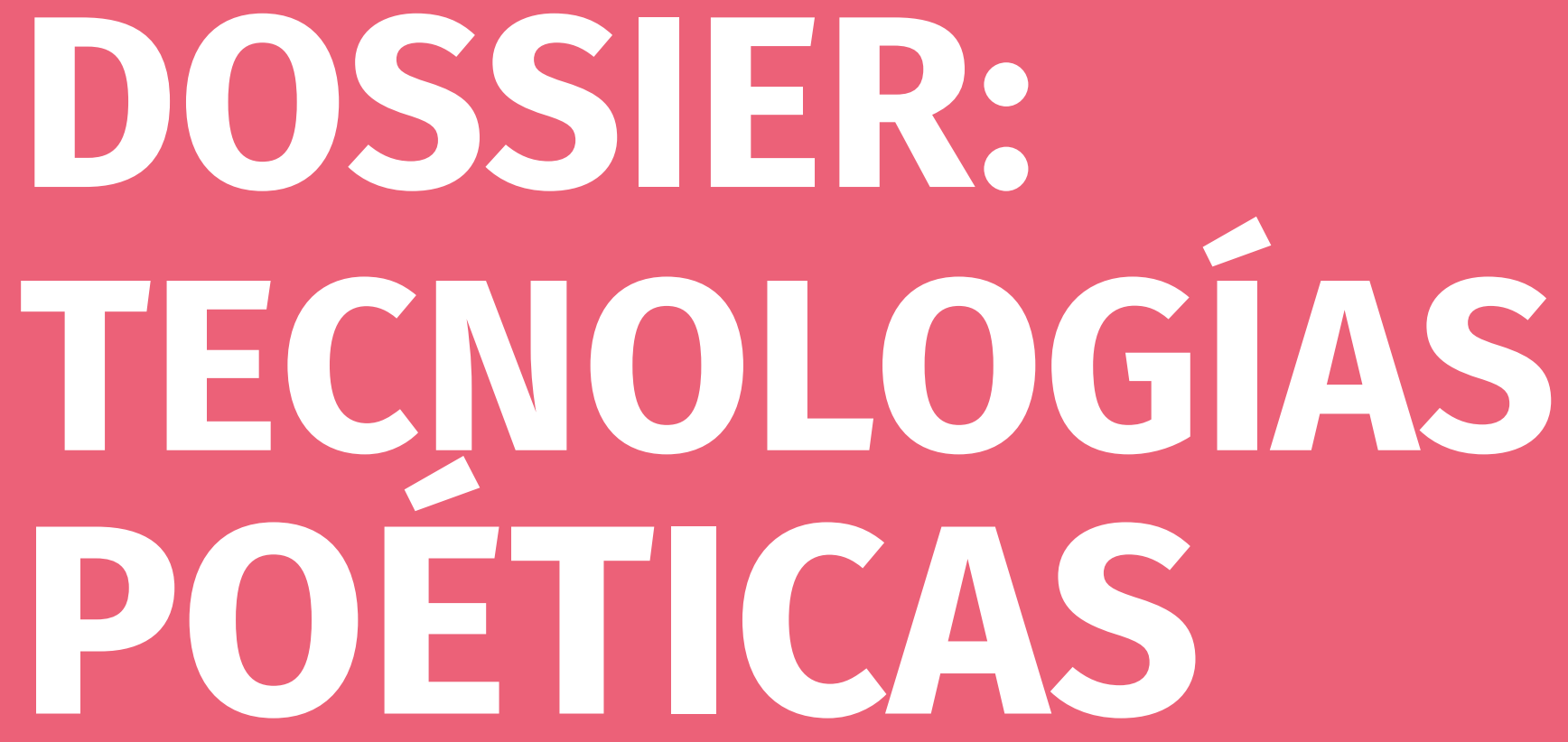

\title{
EN EL ARTE
}

CONTEMPORÁNEO

POETIC TECHNOLOGIES

IN CONTEMPORARY ART 


\section{Hernán Ulm}

Doctor en Literatura comparada por la Universidade Federal Fluminense, Magister y Licenciatura en Filosofía por la Universidad Nacional de Salta. Es profesor de Estética e Historia del Arte y Director del Instituto de Investigaciones en Cultura y Arte en esa Universidad. Sus trabajos de investigación giran en torno a las relaciones entre arte y política, y a las relaciones intermediales entre la literatura, el cine y las artes visuales, tomando como punto de partida el cuestionamiento de las materialidades estéticas que las constituyen. Ha publicado artículos en revistas especializadas y ha ofrecido cursos en Argentina y otros países. Igualmente ha participado denumerosos eventos.

\section{Correo electrónico:}

Hernan_Ulm@yahoo.com

\section{Tatiana Navallo}

Tatiana Navallo es Doctora en Literatura Hispánica por la Universidad de Montreal, donde imparte cursos en el Centro de Lenguas. Es investigadora asociada del Laboratorio Interdisciplinario de Estudios Latinoamericanos (LIELA, Universidad de Quebec en Montreal). Sus trabajos abordan las ficciones de la historia en la narrativa contemporánea, en particular la literatura migrante y las expresiones artísticas transfronterizas. Los resultados de sus investigaciones han sido presentados en coloquios y congresos. Entre sus publicaciones recientes se encuentran las ediciones de números temáticos sobre literatura y arte transfronterizo para Hispanic Studies Review (2018), Letras Hispanas: Revista de Literatura y Cultura (2018), como así también su colaboración en Vues transversales/Récits visuels. Panorama de la scène artistique latino-québécoise (Centre d'histoire de Montréal, CIDIHCA, CALQ, 2018).

\section{Correo electrónico:}

ct.navallo.coimbra@umontreal.ca 


\section{Resumen}

El dossier indaga en torno a las configuraciones de lo sensible en el mundo contemporáneo. La percepción del mundo y de nosotros mismos no es natural, neutra o pura. Siempre está construida a partir de un conjunto de reglas que definen lo que llamamos un "ritual de la percepción". En este sentido, los agenciamientos sociales son, en primer lugar, agenciamientos de lo sensible. Las reglas que operan en la configuración de la sensibilidad pueden tener dos devenires: un devenir técnico y otro artístico. A partir del siglo XX, el agenciamiento de producción de sensibilidad opera a través de la bioinformatización, mediante cálculos algorítmino-digitales. Los textos que se presentan a continuación intentan realizar una reflexión crítica que pone de relieve los alcances de esta mutación, tomando como eje conductor la cuestión del arte.

\section{Palabras clave:}

percepción, producción de sensibilidad, imagen, algoritmo, bioinformatización.

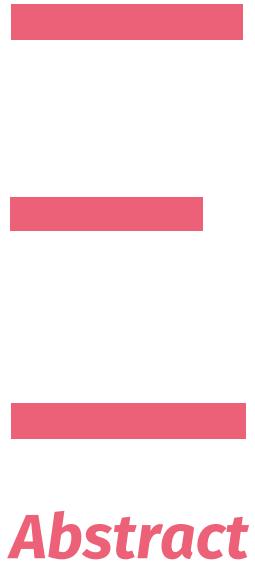

The present dossier delves into the configurations of sensitivity in the contemporary world. The perception of the world and of ourselves is not natural, pure or neutral, as it is always constructed from a conjunction of rules that define what we call a "ritual of perception". Therefore, social agencies are first and foremost agencies of sensitivity. The rules that operate in the configuration of the sensitive can confer two results: the technical and the artistic. Since the 20th century, the agency of sensitivity operates through bioinformatisation, by way of digital algorithmic calculations. The following texts attempt a critical reflection that highlights the scope of such mutation, while presenting art as the common thread.

\section{Keywords:}

perception, production of sensitivity, image, algorithm, bioinformatics. 


\title{
La obra de arte en la era de la sensibilidad bioinformacional
}

\section{El pliegue estético: entre la técnica y el arte}

\author{
广 \\ ¿A qué acontecimiento o a cuál ley obedecen esas \\ mutaciones que hacen que repentinamente las cosas no \\ sean más percibidas, descritas, enunciadas, caracterizadas, \\ clasificadas y fatigadas de la misma manera, y que en el \\ intersticio de las palabras o bajo su transparencia, no sean \\ más las riquezas, los seres vivos, el discurso que se abren \\ al saber, sino seres radicalmente diferentes? \\ Michel Foucault, Las palabras y las cosas. Una arqueología de la ciencias humanas. \\ Buenos Aires: Siglo XXI, 1968, p. 213. (resaltado nuestro)
}

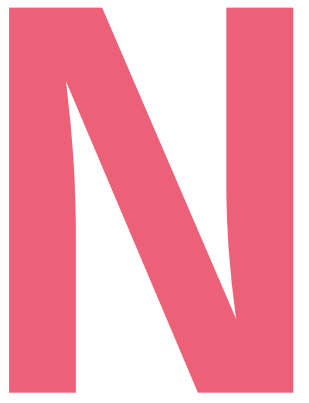

uestras percepciones son producidas en el interior de un agenciamiento social que regula y prescribe el orden normalizado de lo "sensible". En este marco, no existe una "percepción natural", pura, inocente o neutra. Por el contrario, nos encontramos expuestos a rituales de la percepción que configuran los modos de aparecer, especificando los regímenes de sensibilidad diferenciados - propios de cada agenciamiento-, según reglas que en cada caso deben ser seguidas para dar lugar a que "lo común” se constituya. Dicho de otro modo, los agenciamientos sociales son, en primer lugar, agenciamientos de sensibilidad que, según un orden ritualizado por reglas, producen un horizonte común de perceptibilidad. Para formar parte de un agenciamiento, para ser contados y tenidos en cuenta por él, debemos aceptar las reglas que, al tiempo que producen legítimamente lo perceptible, nos producen como legítimamente perceptibles. El rechazo y la no aceptación de esas reglas implica recibir la condena de lo abyecto de aquello que no tendrá lugar, que no será contado y que, consecuentemente, no podrá aparecer. De manera sintética, asumimos que los "rituales de la percepción" conocen dos devenires: uno técnico mediante los cuales se expresa, a través de los aparatos el modo de normalizado de la sensibilidad, mostrándonos los modos correctos del aparecer ${ }^{1}$; otro artístico que nos muestra -en el

1 El estudio de los devenires técnicos se ha presentado, frecuentemente, bajo dos modalidades complementarias: la tecnofilia y la tecnofobia; ambas suponen un carácter sustancial de las técnicas. Nuestra propuesta es alejarnos de esa oposición para pensar el devenir técnico como una de las formas en que se expresan los agenciamientos sociales. 
interior de las prescripciones que organizan los aparatos técnicos- las transgresiones, desterritorializaciones, movimientos de fuga y fractura, que habitan en la sensibilidad agenciada. Técnica y arte constituyen así dos movimientos en el interior de un mismo agenciamiento: la primera, tendiendo a su normalización; el segundo, trabajando las transgresiones que lo agrietan. No hay, entonces, escisión entre técnicas y artes, sino tecnologías poéticas que configuran, en la tensión que las mantiene unidas, el umbral de una común perceptibilidad. De esta manera se hace posible, en nuestra propuesta, una "genealogía del aparecer" que tiene por fin mostrar las diversas discontinuidades y segmentaciones por las que se han producido modos diferenciados del organizar la sensibilidad y las legitimidades del aparecer. En este orden de ideas, un nuevo ritual de la percepción significará que lo que aparecía "legítimamente" en un agenciamiento se hunda más allá de sus fronteras, para que nuevos seres y percepciones "radicalmente diferentes" tengan lugar. En este sentido, comprender nuestro presente no implica no solo realizar la genealogía de los rituales en que tuvo lugar, sino también que el analizar los devenires de nuestras tecnologías poéticas implica interrogar las relaciones que, en la experiencia contemporánea, se establecen entre la técnica y el arte, junto a las condiciones políticas -en tanto condiciones de nuestro "vivir juntos"- que tales tecnologías vienen a expresar.

Si desde el Renacimiento podíamos "vivir juntos" en el interior de un tiempo y un espacio homogéneos, producidos según las reglas ritualizadas de la perspectiva, que ponían al hombre como centro desde el cual se proyectaban los límites de lo que aparecía legítimamente, si se tiene en cuenta que los límites quedaban fijados en el interior de un cuadro; con el devenir algorítmico de la percepción, el tiempo y el espacio no tienen en el hombre su centro, ni se sujetan los límites de lo que se da como aparecer en los marcos del cuadro. Al respecto, cabe aquí una digresión, pues el cuadro no solo garantizaba la unidad espacial de lo que aparecía en su interior -fuera del cuadro, el desierto configuraba el espacio vaciado de la representación colonialista moderna- sino que también garantizaba la unidad temporal en la que la historia narraba el espectáculo de su propia expansión, ya que fuera de la unidad del tiempo histórico aparecía la prehistoria, el tiempo iletrado como tiempo vacío, sin nada que contar. Por su parte, la reducción algorítmica, en términos de Vilém Flusser (1990), rompe los mencionados marcos de la representación y produce "un espacio" - "inmediato" de no mediación, de circulación- y "un tiempo" -el instante- cerodimensionales, que no pueden ser percibidos sino a través de aparatos bioinformáticos como el celular o el computador, en los que el cuerpo parece ser una interfase de su funcionamiento. En este sentido, con Gilles Deleuze (2017), podemos afirmar que estos aparatos producen no tanto formas de sujeción sino nuevos modos de servidumbre. Así, en los agenciamientos neoliberales de control social, el cuerpo mecánico deja su lugar a un cuerpo bionformatizado cuya condición de aparición ya no es causal sino estadística. Producidos algorítmicamente, el espacio y el tiempo dejan de ser las configuraciones en las que el cuerpo se aloja para convertirse en las resultantes de un cálculo al que el cuerpo debe obedecer. En cambio,

en los mundos virtuales, el espacio deja de ser una forma a priori. Él mismo se convierte en una imagen que hay que formalizar, modelar. Podemos darnos con toda libertad un espacio euclidiano, un espacio de Riemann o de Lobatchevsky o incluso un espacio con propiedades arbitrarias (Quéau, 1995, p. 21-22. Destacados del autor).

Solo porque el espacio se calcula como inmediatez, solo porque el tiempo se calcula como instante, hay interconectividad, pura intercambiabilidad. Así mismo, solo porque hay instante, inmediatez e intercambiabilidad se deja de hacer la experiencia del otro como mediación: todo pasaje por el/la/lo otra/o es visto ahora como un ruido, una interferencia, una demora, un desvío que es necesario evitar. Toda mediación es así una interrupción en el sistema generalizado de intercambiabilidad neoliberal. 


\section{La sensibilidad bioinformatizada}

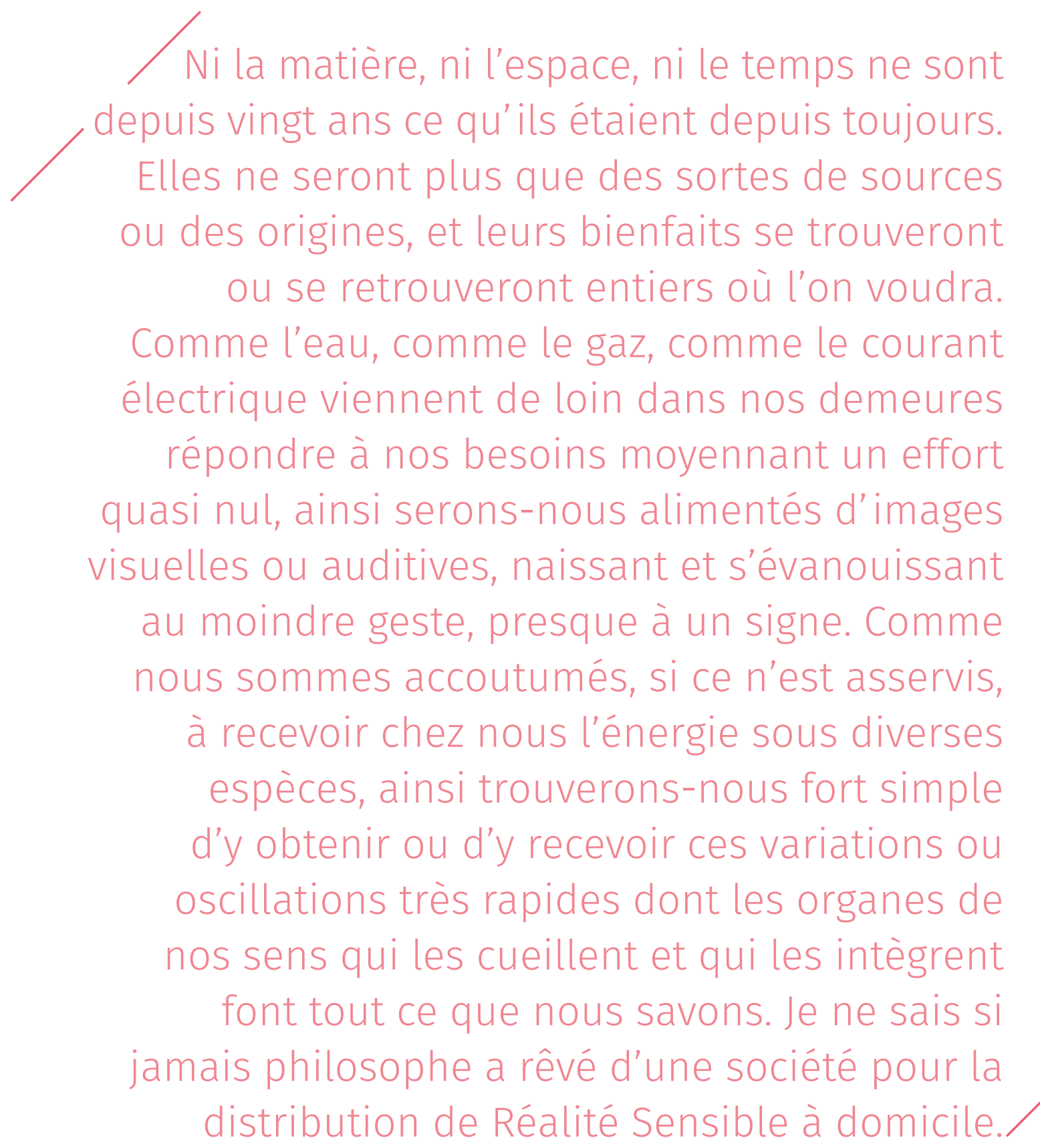

Paul Valéry, La conquête de l'ubiquité de la ubiquité, 1928. 
Sentados frente a nuestro computador, mientras el celular insiste en darnos avisos de citas que habríamos preferido olvidar, escribiendo a través de pantallas compartidas el artículo para una presentación, podemos escuchar músicas provenientes de regiones cuya ubicación cartográfica ignoramos (pero que un software no tarda en revelarnos), o mirar algún filme "online" (cuya "resolución" garantiza una imagen sin pérdida), de modo tal que nuestros "amigos" de las "redes sociales" se enteran, "en tiempo real", de nuestros gustos secretos y nuestras ambiciones íntimas². Más aún, la puesta en red de nosotros mismos nos brinda satisfacción inmediata, ofreciendo, sin que lo pidamos, garantía de plenitud ante el temor al que nos lanza el vacío de nuestros deseos: anticipación que arruina cualquier erotismo -al menos tal como lo podíamos concebir con Georges Bataille-y nos entrega, a cambio, la esperanza de un consumo que no deja nada librado al azar: son seres "radicalmente diferentes" los que se nos aparecen en las superficies bioinformatizadas del cálculo digital. Somos seres "radicalmente diferentes" en nuestro modo de aparecer en el flujo informático digital, si se piensa en el umbral que separa, irremediablemente, la forma moderna del "espacio público" -concebido a partir del modelo lecto-escritor-y nuestra manera de aparecer como publicidad en las redes de interconectividad mundial: el modelo lecto-escritor, supone, al menos, el espesor de un tiempo en el que la lectura exige la comprensión y la crítica, mientras que la compulsión

2 Como la mayor parte de las metáforas informático-digitales, la de la "resolución" de la "calidad de la imagen" abre, en la riqueza semántica de sus sentidos, una vía de comprensión de las paradojas que encierran nuestra tecnología poética. Si una resolución es un modo de clausura de un problema y asi, un modo que anuncia una liberación, la "resolución de imagen", en tanto liberación de la información contenida en esta, determina no solo la calidad de la recepción sino también las posibilidades de circulación de datos. La alta y la baja resolución reproduce, a una escala inesperada, las distinciones de clase de la sociedad neoliberal. Así, las metáforas de la memoria y del peso de las imágenes son complementarias de esta y abren nuevas paradojas para explorar. del instante exige que demos respuesta inmediata a las demandas de la política actual.

En resumen, la promesa de Paul Valéry de una "realidad sensible a domicilio", elaborada en los albores del siglo XX -con solo una luz oscilante que se ve atravesando el nacimiento eléctrico de nuestro presente algorítmico- parece hoy ampliamente consumada. Si el poeta francés realizaba su diagnóstico a partir de la emergencia de los medios mecánicos de reproducción de imágenes -la fotografía, la máquina de escribir, el fonógrafo y el cine-, con la reducción informático digital de lo existente -de la genética a la exploración espacial-, expresada en aparatos de bionformatización de la sensibilidad -de la computadora al celular-, a un enter de distancia, se encuentra la realidad tan disponible para nosotros, como nosotros dispuestos para ésta. Lo que vemos y lo que oímos son producidos según las fórmulas algorítmicas de un cálculo que, o bien ya no podemos o bien no siempre podemos acompañar. Por esto mismo, nuestros ojos y nuestros oídos son bioterminales incorporadas -nunca más precisa esta palabra- en el movimiento incesante del flujo de datos del aparato digital ya que, tal como nos lo ha marcado la experiencia de la Segunda Guerra Mundial, nos encontramos en un estado de "movilización permanente" ${ }^{\prime}$. Nuestro cuerpo deviene así en parte del hardware necesario para que los programas puedan funcionar, en un mundo que no es algo que "está allí afuera" sino el efecto previsible de un cálculo informacional. El referente de la sensibilidad digital es, en todo caso, el propio proceso de producción de la percepción que opera intensivamente en la estabilización de lo sensible. De este modo, "lo que aparece" -es decir, lo

\footnotetext{
3 Respecto de las importancia de la Segunda Guerra mundial para el desarrollo tecnológico de nuestro presente, ver La verdad del mundo técnico. Ensayos para una genealogía del presente de Friedrich Kittler (2018). Para un acercamiento diferente en torno a la cuestión del estado de movilización permanente como condición de nuestro presente, ver Fredric Jameson, El posmodernismo o la lógica cultural del capitalismo tardío (1991).
} 
que define las tecnologías poéticas de nuestro "vivir juntos"- lo hace bajo el aspecto de informaciones codificadas que debemos saber, eventualmente, decodificar: solo será perceptible aquello que se deja producir como información, aquello que se deja calcular. Lo que no se produzca según estos principios será olvido digital, como bien indican -y no en vano-, las metáforas de la memoria que acompañan las formas computarizadas de la vida contemporánea. En este marco, de acuerdo a Hans Belting (2009),

el cambio en la experiencia de la imagen expresa también un cambio en la experiencia del cuerpo, por lo que la historia cultural de la imagen, se refleja también en una análoga historia cultural del cuerpo [...] Los medios digitales de la actualidad modificaron nuestra percepción, al igual que lo hicieron los medios técnicos que les antecedieron; sin embargo esta percepción permanece ligada al cuerpo (p. 30-31).

Si, como sostiene Flusser en Filosofía de la fotografía, el devenir algorítmico de la percepción se concentra en la caja negra que oculta el secreto que hace funcionar al aparato -sea este el aparato perceptivo, el burocrático político, el económico neoliberal- buena parte del devenir de nuestras tecnologías poéticas consiste en operar en el "interior" de esas cajas negras, trayendo a la discusión los principios que la hacen funcionar. En síntesis, la pretendida democratización que los nuevos medios de producción de lo sensible prometen como principio de igualdad, no deja de expresar también el principio por el cual la homogeneización digital produce una equivalencia algorítmica que, lejos de establecer los principios generales de una comunicación pública, la reemplaza por la lógica informática propia de la red militar4.

4 De acuerdo a Friedrich Kittler (2018), la noción de "red" tiene lugar en la formulación de nuevas estrategias que operan el cambio de la "guerra de trincheras" a la "guerra relámpago": la primer puesta en red fue llevada a cabo gracias a los sistemas de comunicación desarrollados por el ejército alemán, lo cual permitió conectar de forma segura a los altos mando militares con el cuerpo de tanques en la avanzada militar.

\section{Acerca de este dossier: interrogar las poéticas tecnológicas}

De acuerdo a lo apuntado, hemos asistido a una destrucción general de las categorías que, desde el Renacimiento, producían un cuerpo mecánico y causal al interior de cuadros cuyos límites establecían los marcos de la aparición -desde los evidentes marcos de las representaciones pictóricas, hasta los marcos metafóricos como las tapas de los libros, que enmarcaron el saber legítimo de lo que se debía transmitir y enseñar, o los marcos políticos que encontraban en las formas indirectas de la representación su modo legítimo de actuar. El agenciamiento neoliberal que produce nuestra percepción, organiza el régimen de lo sensible, como flujos continuos de información que circulan y se intercambian, interminablemente, fuera de cuadro ${ }^{5}$. Es pues en este contexto, que la pregunta que Walter Benjamin lanzara hace ya casi cien años, conminándonos a reinventar un sentido posible para la noción del arte -y de la política-, vuelve a encontrar su lugar. Sin embargo, como indica Sergio Martínez Luna en este dossier, ya no

5 Una versión exaltada de esta tecnología poética, incluidas las loas de su expansión ilimitada, se puede leer en la obra de Kevin Kelly, promotor de la puesta en red de las cinco bibliotecas más importantes de Estados Unidos. Una respuesta a la propuesta tecnofilica de Kelly se puede consultar en La marca del editor, de Roberto Calasso (2015). Para tomar una medida más precisa de las implicancias que este pensamiento tiene entre los propulsores del devenir técnico, se puede consultar Lo inevitable. Entender las 12 fuerzas tecnológicas que configurarán nuestro futuro, de Kevin Kelly. En este marco, Kelly (2017) indica: “La continuación y expansión de las tendencias que describo supondrán un reto para los actuales supuestos legales, y estará prácticamente fuera de la ley: un obstáculo para los ciudadanos que respetan las leyes. Por su naturaleza, la tecnología de las redes digitales alterará las fronteras internacionales porque ella misma no tiene fronteras. Habrá sufrimiento, conflictos y confusión, además de unos beneficios increíbles" (p. 4). Las fronteras han sido, como ya ha sido suficientemente analizado, uno de los primeros marcos que el neoliberalismo globalizado ha derribado en su producción de sensibilidad en flujo. 


\section{El agenciamiento neoliberal que produce nuestra percepción, organiza el régimen de lo sensible, como flujos continuos de información que circulan y se intercambian, interminablemente, fuera de cuadro.}

podemos abandonarnos a la confianza según la cual las contradicciones internas del capitalismo llevarían a su superación.

De lo dicho se desprende que el arte -pese y contra Kelly-, y sus formas de agrietar el agenciamiento al que pertenecemos, no cesa de trabajar en ese fuera de marco del flujo informacional, como bien lo ilustran las propuestas de los autores aquí reunidos. Sea la práctica literaria, que no deja de apropiarse de los flujos que desplazan las funciones autorales, llevando tanto a lectores como a escritores a intercambiar sus lugares, hasta que el propio algoritmo se pone a delirar en ese fuera de texto que él mismo produce, de acuerdo a los aportes de Rafael Gutiérrez y Santiago Martín de Salterain; sea el análisis de las imágenes y sus tipologías, de una a otras, las materialidades respectivas que las producen modifican los sentidos de las que son portadoras revelando, así, la materialidad que las inscribe y que las hace migrar en su eterna puesta en circulación, según Fernando Pérez Villalón; sea explorando los límites en los que el arte y la vida abren flujos de un intercambio, en el que las fuerzas biológicas y las fuerzas de la obra producen nuevos existentes, que cuestionan políticamente la organización informacional de la vida, en los términos plan- teados por Ayelén Zaretti y Emiliano Sacchi; sea en la práctica que afirma, desde el arte y con sus disímiles intervenciones, la restitución de una memoria que no siempre encuentra lugar en un archivo digital y por lo cual es preciso inventarle una huella que no se deje olvidar, como bien lo apuntan las propuestas de Yamila Volnovich, Celina Van Dembroucke, Rubén Yepes y Pablo Domínguez Galbraith.

A manera de cierre, nos resta subrayar que, como todo agenciamiento, nuestro presente se ve atravesado simultáneamente por un doble devenir: por una parte, el tecno-paranoico -resultado de la reducción algorítmico-digital de nuestro entorno sensible al principio único del cálculo informacional-, como así mismo aquel otro devenir que, al transgredir las paranoias, las conecta en otro lugar. Los trabajos que presentamos aquí intentan atravesar el borde en el que esa trasgresión se vuelve un acto creativo, traducido a su vez en resistencia política. Se trata, retomando a Michel Foucault, de apropiarnos de las reglas que producen lo que somos, mediante un acto de torsión no exento de crueldad, para dejar de ser lo que se espera de nosotros. Esa práctica de la crueldad que nos posibilita, desde Antonin Artaud, el quehacer de lo que denominamos arte. 


\section{Referencias}

» Belting, H. (2009). Antropología de la imagen. Buenos Aires: Katz.

" Calasso, R. (2015). La marca del editor. Barcelona: Anagrama.

»Deleuze, G. (2017). Derrames 2. Aparatos de Estado y axiomática capitalista. Buenos Aires: Cactus.

"Flusser, V. (1990). Hacia una filosofía de la fotografía. México: Sigma.

» Foucault, M. (1966). Les mots et les choses. Une arquéologie des sciences humaines. Paris: Galimard.

» Jameson, F. (1991). El posmodernismo o la lógica cultural del capitalismo tardío. Barcelona: Paidós.

» Kelly, K. (2017). Lo inevitable. Entender las 12 fuerzas tecnológicas que configurarán nuestro futuro. España: Teell.

» Kittler, F. (2018). La verdad del mundo técnico. Ensayos para una genealogía del presente. México: FCE.

» Valéry, P. (1928). La conquête de l' ubiquité. Recuperado de http://classiques.uqac.ca/classiques/ Valery_paul/conquete_ubiguite/conquete_ubiquite.html

» Quéau, P. (1995). Lo virtual. Virtudes y vértigos. Barcelona: Paidós. 